\title{
Estimating hydraulic conductivity from piezocone soundings
}

\author{
J. C. $\mathrm{CHAI}^{*}$, P. M. A. AGUNG* T. HINO*, Y. IGAYA† and J. P. CARTER
}

\begin{abstract}
A method for estimating the hydraulic conductivity of soils from piezocone penetration tests is suggested in this paper. By invoking Darcy's law over the finite time required for an increment of cone penetration, it is argued that there will be some water movement through the soil around the cone, albeit very small if the soil is very fine grained. Based on this argument, and noting the comprehensive test data collected previously by Elsworth \& Lee, a bi-linear relation between the dimensionless piezocone sounding metric $B_{\mathrm{q}} Q_{\mathrm{t}}$ and the dimensionless hydraulic conductivity index $K_{\mathrm{D}}$ plotted on double logarithmic scales has been proposed for soils ranging from sands to clays. It is demonstrated that these revised relationships can be used to evaluate plausible values of hydraulic conductivity from piezocone sounding records taken at two different clay soil sites in Saga and Yokohama, Japan. The major significance of this work is in extending the range of application of the method first proposed by Elsworth \& Lee for sands to almost all soil types. This was possible after appropriate modification of Elsworth and Lee's original method.
\end{abstract}

KEYWORDS: clays; sands
La présente communication propose une méthode d'estimation de la conductivité hydraulique des sols à partir de sondages au piézocône. En invoquant la loi de Darcy sur le temps fini nécessaire pour une augmentation de la pénétration du cône, on soutient qu'un certain mouvement d'eau se produit dans le sol entourant le cône, et qu'il s'agit d'un mouvement de très faible envergure si l'on est en présence d'un sol à grains fins. Sur la base de cet argument, et en prenant note des données d'essai complètes recueillies précédemment par Elsworth et Lee, on a proposé une relation bi-linéaire entre la mesure du sondage au piézocône sans dimensions $B_{\mathrm{q}} Q_{\mathrm{t}}$ et l'indice de conductivité hydraulique sans dimensions $K_{D}$ tracé sur des échelles double-lorgarithmiques proposées pour des sols allant des sables aux argiles. On démontre que ces rapports révisés peuvent être utilisés pour évaluer des valeurs plausibles de la conductivité hydraulique à partir de relevés de sondage au piézocône, effectués sur des sites de sols argileux, à Saga et à Yokohama, au Japon. Limportance du présent ouvrage est qu'il étend la plage d'applications de la première méthode, proposée par Elsworth et Lee pour les sables, à pratiquement tous les types de sol, ce qui a été rendu possible grâce à une modification appropriée de la méthode originale d'Elsworth et Lee.

\section{INTRODUCTION}

The piezocone penetration test (uCPT) is an economic and efficient site investigation method that is widely used in geotechnical engineering practice (Campanella \& Robertson, 1988; Lunne et al., 1997; Mitchell \& Brandon, 1998). The uCPT provides near-continuous measurements of tip resistance $q_{\mathrm{t}}$, sleeve friction $f_{\mathrm{s}}$ and pore water pressure $u$ at the shoulder, or face, or shaft of the cone. These measurements can be used to classify the soil strata (Douglas \& Olsen, 1981; Robertson, 1990; Cetin \& Ozan, 2009) and estimate the shear strength of the deposit (Konrad \& Law, 1987; Rad \& Lunne, 1988; Teh \& Houlsby, 1991; Lu et al., 2004). In clayey deposits, the cone can be halted at a predetermined depth in order to measure the pore pressure dissipation process. The dissipation results can then be used to evaluate the coefficient of consolidation of the soil at that depth, generally using the theoretical results for the corresponding consolidation problem (Gupta \& Davidson, 1986; Teh \& Houlsby, 1991; Robertson et al., 1992; Danziger et al., 1997; Burns \& Mayne, 1998; Sills \& Hird, 2005).

Since a dissipation test often takes significant time, efforts have been made to evaluate the hydraulic conductivity of soil, $k$, using alternative methods, such as the use of piezocone sounding records that do not involve halting the ad-

Manuscript received 10 January 2010; revised manuscript accepted 10 August 2010. Published online ahead of print 25 January 2011. Discussion on this paper closes on 1 January 2012, for further details see p. ii.

* Saga University, Japan.

$\dagger$ Ariake Sea Coastal Road Development Office, Saga Prefecture, Japan.

¿ University of Newcastle, Australia. vance of the cone penetrometer (Clarke et al., 1979; Randolph \& Wroth, 1979; Robertson et al., 1992; Lunne et al., 1997; Sully et al., 1999; Elsworth \& Lee, 2005, 2007). Most of the existing methods of interpretation of this type of test are empirical, and only the method proposed by Elsworth \& Lee $(2005,2007)$ has a semi-rigorous theoretical basis, for which an explicit equation has been derived. However, Elsworth \& Lee's method is applicable only for partially drained conditions, and specifically it is not applicable for clay deposits deforming under conditions that are close to undrained.

In this paper, Elsworth \& Lee's method is briefly reviewed and discussed, and then a means of extending the method to clay soils is presented, resulting in a modified equation for clays and other soils. The proposed method has been used to estimate the hydraulic conductivities of clay deposits in Japan from a variety of piezocone soundings. In total, 24 sounding records have been used, of which 23 are from Saga and one from Yokohama. The estimated values of hydraulic conductivity are compared with corresponding values from laboratory oedometer test results obtained using undisturbed soil samples. A discussion of the usefulness of the proposed method is also presented.

\section{REVIEW OF ELSWORTH \& LEE's METHOD}

The method proposed by Elsworth \& Lee (2005) is based on a dislocation model (Elsworth, 1991). The basic assumption is that during the piezocone penetration, 'dynamic steady' spherical flow of pore water will form around the tip of the cone. The diameter of the spherical cavity is assumed to be the same as the diameter of the cone, and the rate of spherical flow of pore water through the 
periphery of the cavity is assumed equal to the rate of volume penetration, $\Delta \dot{v}$, of the cone (the continuity assumption). Using Darcy's law applied to spherical flow, and assuming that zero excess pore water pressure exists at an infinite distance from the cone, an explicit equation has been derived to calculate the hydraulic conductivity from the piezocone sounding records. The basic concept behind this method is illustrated in Fig. 1, in which $k$ is the hydraulic conductivity, $a$ is the radius of the cone, $U$ is the rate of cone penetration, $i_{\mathrm{a}}$ is the hydraulic gradient at radius $r=a, u_{\mathrm{a}}$ is the absolute pore water pressure measured by the piezocone, and $u_{\mathrm{s}}$ is the initial static pore water pressure. The equation proposed by Elsworth \& Lee (2005) for calculating the in situ value of $k$ is

$$
k=\frac{K_{\mathrm{D}} U a \gamma_{\mathrm{w}}}{4 \sigma_{\mathrm{v} 0}^{\prime}} \text { or } K_{\mathrm{D}}=\frac{4 k \sigma_{\mathrm{v} 0}^{\prime}}{a \gamma_{\mathrm{w}} U}
$$

where $\gamma_{\mathrm{w}}$ is the unit weight of water and $\sigma_{\mathrm{v} 0}^{\prime}$ is the initial vertical effective stress. $K_{\mathrm{D}}$ is a dimensionless hydraulic conductivity index, which can also be expressed as

$$
K_{\mathrm{D}}=\frac{1}{B_{\mathrm{q}} Q_{\mathrm{t}}}
$$

where $B_{\mathrm{q}}$ and $Q_{\mathrm{t}}$ are the dimensionless pore water pressure ratio and dimensionless tip resistance respectively, defined as (Wroth, 1984)

$$
\begin{aligned}
B_{\mathrm{q}} & =\frac{u_{\mathrm{a}}-u_{\mathrm{s}}}{q_{\mathrm{t}}-\sigma_{\mathrm{v} 0}} \\
Q_{\mathrm{t}} & =\frac{q_{\mathrm{t}}-\sigma_{\mathrm{v} 0}}{\sigma_{\mathrm{v} 0}^{\prime}}
\end{aligned}
$$

where $q_{\mathrm{t}}$ is the total cone tip resistance, and $\sigma_{\mathrm{v} 0}$ is the initial total vertical stress.

As explained by Elsworth \& Lee (2005, 2007), equation (1) can be used only for the case of partially drained conditions in the soil ahead of and surrounding the cone penetrometer. This means that the value of $k$ of the soil must be low enough for excess pore water pressure to be generated, and at the same time it must also be high enough to allow formation of 'dynamic steady' pore water flow around the cone.

Elsworth \& Lee (2007) collected some of the available data from field piezocone soundings and independently measured hydraulic conductivity values, $k$, for the same soils. A comparison of these two sets of values of hydraulic conductivity is presented in non-dimensional form in Fig. 2. Elsworth \& Lee suggested that equation (1) should be used only for $B_{\mathrm{q}} Q_{\mathrm{t}}<1 \cdot 2$, that is, for soils with $k>10^{-5} \mathrm{~m} / \mathrm{s}$, which corresponds to fine sand.

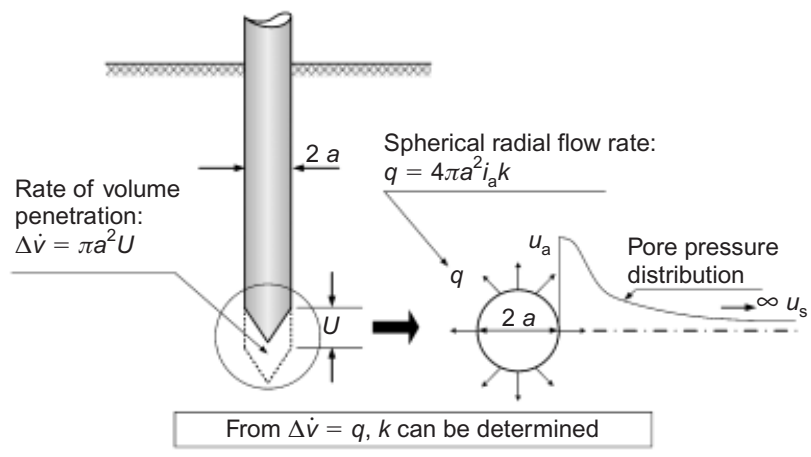

Fig. 1. Basic concept of Elsworth \& Lee's (2005) method

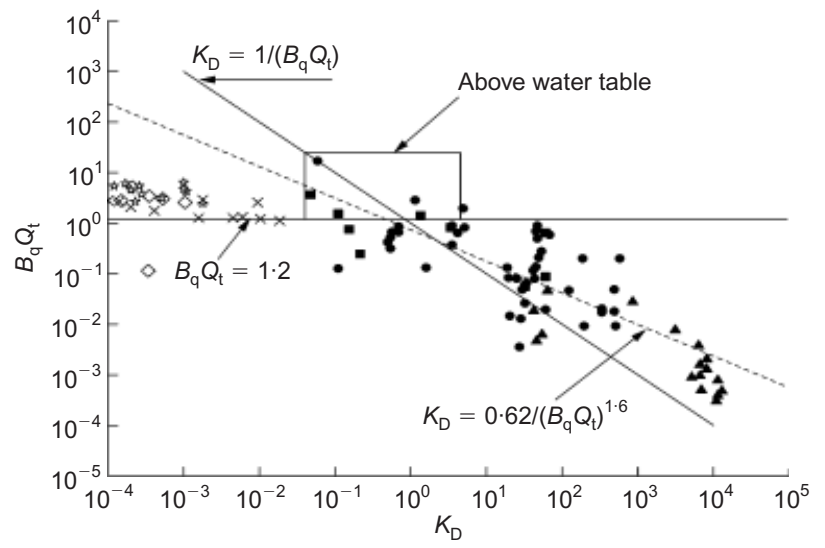

Fig. 2. Relationship between measured non-dimensional hydraulic conductivity $K_{\mathrm{D}}$ and $B_{\mathrm{q}} Q_{\mathrm{t}}$ from piezocone test (data from Elsworth \& Lee, 2007)

As shown in Fig. 2, even for the region corresponding to $B_{\mathrm{q}} \mathrm{Q}_{\mathrm{t}}<1 \cdot 2$, the line defined by $K_{\mathrm{D}}=1 /\left(B_{\mathrm{q}} Q_{\mathrm{t}}\right)$ does not provide the best fit to the measured data. As a consequence, Elsworth \& Lee (2007) modified the $K_{\mathrm{D}}-B_{\mathrm{q}} Q_{\mathrm{t}}$ relation and suggested that the following (empirical adjustment) was more appropriate in practice

$$
K_{\mathrm{D}}=\frac{\alpha}{\left(B_{\mathrm{q}} Q_{\mathrm{t}}\right)^{\beta}}
$$

where $\alpha$ and $\beta$ are constants. Elsworth \& Lee suggested that suitable values were $\alpha=0.62$ and $\beta=1 \cdot 6$.

\section{MODIFICATION OF ELSWORTH \& LEE's METHOD}

In an infinite porous medium, under the condition that excess pore water pressure is zero for radial distance $r \rightarrow$ $\infty$, for steady water flow from a spherical cavity, the distribution of pore water pressure $u$ can be expressed as

$$
u-u_{\mathrm{s}}=\left(u_{\mathrm{a}}-u_{\mathrm{s}}\right) \frac{a}{r}
$$

In such cases the hydraulic gradient ( $i$ ) at $r=a$ is

$$
\begin{aligned}
\left.i\right|_{r=a} & =i_{a}=\left.\frac{1}{r_{\mathrm{w}}} \cdot \frac{\mathrm{d} u}{\mathrm{~d} r}\right|_{r=a}=\frac{u_{\mathrm{a}}-u_{\mathrm{s}}}{a \gamma_{\mathrm{w}}} \\
& =B_{\mathrm{q}} Q_{\mathrm{t}} \frac{\sigma_{\mathrm{v} 0}^{\prime}}{a \gamma_{\mathrm{w}}}=\frac{1}{K_{\mathrm{D}}} \cdot \frac{\sigma_{\mathrm{v} 0}^{\prime}}{a \gamma_{\mathrm{w}}}
\end{aligned}
$$

The expression for $i_{a}$ in equation (7) depends only on the measured value of $u_{\mathrm{a}}$, the value of the static pore water pressure $u_{\mathrm{s}}$, the unit weight of pore fluid $\gamma_{\mathrm{w}}$ and the radius of the cone $a$, and does not include any soil material property. Therefore it should be applicable to all saturated porous media, regardless of soil type.

Assuming that the rate of 'dynamic steady' flow through the periphery of the cavity with a radius $a$ is linearly proportional to the rate of volume penetration of the cone, $\Delta \dot{v}\left(=\pi a^{2} U\right)$, we obtain

$$
4 \pi a^{2} k i_{a}=\alpha_{1} \pi a^{2} U
$$

where $\alpha_{1}$ is a constant of proportionality that should be equal to or less than 1.0. Physically, $\alpha_{1}<1$ means that the rate of 'dynamic steady' flow out of the cavity is less than the rate of volume penetration of the cone. Substituting $i_{a}$ from equation (7) into equation (8), and introducing $K_{\mathrm{D}}^{\prime}=\alpha_{1} K_{\mathrm{D}}$, we obtain the equation 


$$
\begin{aligned}
K_{\mathrm{D}}^{\prime} & =\alpha_{1} K_{\mathrm{D}} \\
& =\frac{\alpha_{1}}{B_{\mathrm{q}} Q_{\mathrm{t}}}=\frac{4 k \sigma_{\mathrm{v} 0}^{\prime}}{a \gamma_{\mathrm{w}} U}
\end{aligned}
$$

Comparison of equations (1) and (9) indicates that altering the continuity condition changes the $k-K_{\mathrm{D}}$ relationship. To keep the form of equation (1), the definition of $K_{\mathrm{D}}$ has to be modified. Equation (9) suggests the use of $K_{\mathrm{D}}^{\prime}$ instead of $K_{\mathrm{D}}$, so that the form of equation (1) is maintained. Equation (5) also provides a way of modifying the definition of $K_{\mathrm{D}}$. However, equation (9) has a clearly identifiable physical basis, whereas equation (5) is merely a 'best-fit' expression to the data collected by Elsworth \& Lee (2007). Equating $K_{\mathrm{D}}^{\prime}$ in equation (9) with the $K_{\mathrm{D}}$ in equation (5) (i.e. $\left.\alpha_{1} /\left(B_{\mathrm{q}} Q_{\mathrm{t}}\right)=0 \cdot 62 /\left(B_{\mathrm{q}} Q_{\mathrm{t}}\right)^{1 \cdot 6}\right)$ indicates that, for $B_{\mathrm{q}} Q_{\mathrm{t}} \geqslant 0.45$, $\alpha_{1} \leqslant 1$. However, for $B_{\mathrm{q}} Q_{\mathrm{t}}<0.45, \alpha_{1}>1$ is required, which is not physically justified.

Further, as shown in Fig. 3, during the piezocone penetration water cannot flow into the cone (i.e. in the direction shown by the arrow A). Therefore it is more appropriate to assume that the surface area for water flow is only a half sphere, in which case equations (8) and (9) can be modified as

$$
\begin{aligned}
& 2 \pi a^{2} k i_{a}=\alpha_{1} \pi a^{2} U \\
& \alpha_{1} K_{\mathrm{D}}=\frac{2 k \sigma_{\mathrm{v} 0}^{\prime}}{a \gamma_{\mathrm{w}} U}
\end{aligned}
$$

For $\alpha_{1}=1$, equation (9a) becomes

$$
K_{\mathrm{D}}=\frac{2 k \sigma_{\mathrm{v} 0}^{\prime}}{a \gamma_{\mathrm{w}} U}
$$

Equation (10) can be considered as a reasonable alternative to equation (1). It will be used as the basic equation for calculating $k$ from $K_{\mathrm{D}}$, or vice versa, in the modified method suggested in this paper.

Using equation (10), the values of $K_{\mathrm{D}}$ calculated from the measured data collected by Elsworth \& Lee (2007) will become exactly half the values they reported. Fig. 4 shows a plot of the newly calculated $K_{\mathrm{D}}$ values. From observation, it is proposed that for $B_{\mathrm{q}} Q_{\mathrm{t}}<0 \cdot 45$, the relationship given by

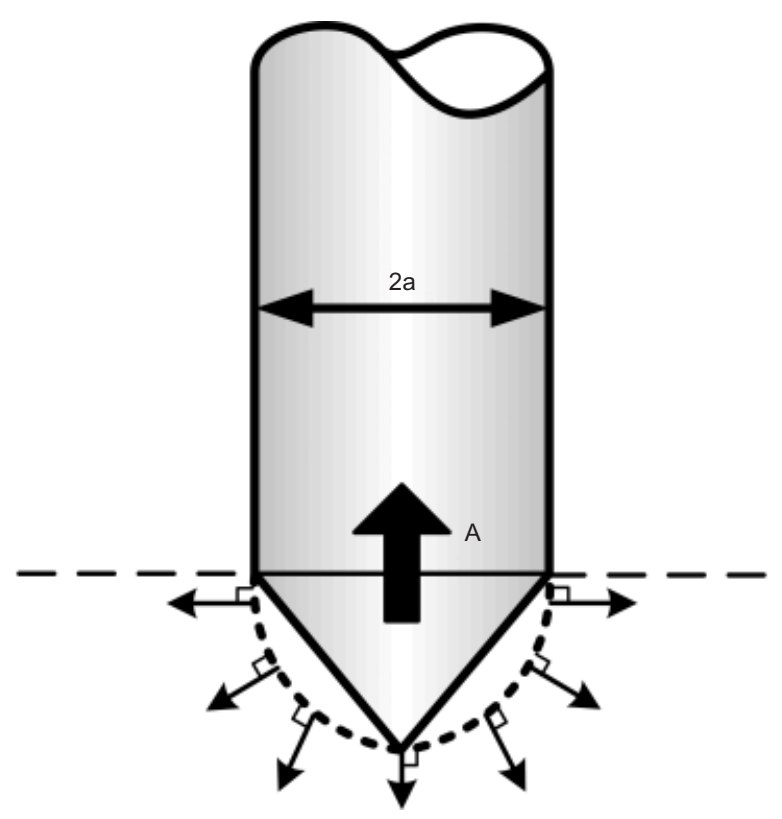

Fig. 3. Half-spherical flow

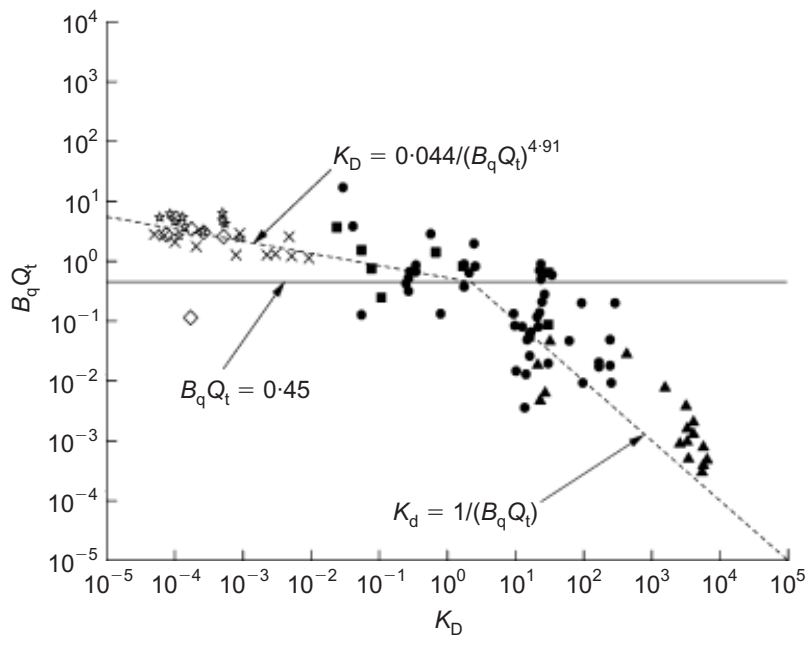

Fig. 4. Proposed bi-linear $K_{\mathrm{D}}-B_{\mathrm{q}} Q_{\mathrm{t}}$ relationship (data points modified from Elsworth \& Lee, 2007)

$K_{\mathrm{D}}=1 /\left(B_{\mathrm{q}} Q_{\mathrm{t}}\right)$ can still be used (corresponding to $\alpha_{1}=1 \cdot 0$ in equation (8a)).

The major obstacle to using Elsworth \& Lee's (2005, 2007) method for clayey deposits is that the penetration process corresponds quite closely to undrained conditions, implying that there can be no water movement involved. For uCPT tests in clayey soils, it is generally agreed that the penetration resistance is controlled mainly by the undrained shear strength of the soil. However, during the penetration process there will be hydraulic gradients generated around the tip of the cone. According to Darcy's law there must therefore be some water movement during the finite time taken for cone penetration, even though the volume of water flowing may be very small. Physically, this requirement means that the flow rate must be only a very small portion of the rate of volume penetration of the cone: that is, the value of $\alpha_{1}$ in equation (8a) should be very small, and therefore $K_{\mathrm{D}}<<1 / B_{\mathrm{q}} Q_{\mathrm{t}}$. If this argument is accepted, then on observing the plot presented in Fig. 4, a relationship between $K_{\mathrm{D}}$ and $B_{\mathrm{q}} Q_{\mathrm{t}}$ for $B_{\mathrm{q}} Q_{\mathrm{t}} \geqslant 0.45$ is proposed as

$$
K_{\mathrm{D}}=\frac{0 \cdot 044}{\left(B_{\mathrm{q}} Q_{\mathrm{t}}\right)^{4 \cdot 91}} \quad\left(B_{\mathrm{q}} Q_{\mathrm{t}}>0 \cdot 45\right)
$$

In determining the expression presented in equation (11), the following two factors have been considered.

(a) $K_{\mathrm{D}}$ values (and thus the value of $k$ ) deduced from field uCPT tests should represent mainly the hydraulic conductivity of a natural deposit in the horizontal direction. Owing to the stratification commonly observed in natural soil deposits, the hydraulic conductivity in the horizontal direction, $k_{\mathrm{h}}$, is often larger than that in the vertical direction, $k_{\mathrm{v}}$ (e.g. Leroueil et al., 1990). Although there is no information given by Elsworth \& Lee (2007) on whether the $k$ values collected are $k_{\mathrm{v}}$ or $k_{\mathrm{h}}$, most laboratory consolidation tests are conducted with the samples cut in the vertical direction with respect to the in situ condition. The proposed equation should consider this factor.

(b) Reference has been made to the uCPT tests as well as laboratory oedometer test results conducted in Saga, Japan, to be described in the following section.

Equation (11) is a straight line in a double logarithmic scale, as shown in Fig. 4, and the appropriateness of the proposed bi-linear relationship may be seen. For example, for 
$B_{\mathrm{q}} Q_{\mathrm{t}}=3$, the value of $K_{\mathrm{D}}$ calculated by equation (11) is only about $0.06 \%$ of the value of $1 /\left(B_{\mathrm{q}} Q_{\mathrm{t}}\right)$, which implies that the flow rate is only about $0.06 \%$ of the rate of volume penetration of the cone, $\Delta \dot{v}$. For a standard cone with a cross-sectional area of $1000 \mathrm{~mm}^{2}$ and penetration rate of $20 \mathrm{~mm} / \mathrm{s}, \Delta \dot{v}=20000 \mathrm{~mm}^{3} / \mathrm{s}$, and $0.06 \%$ of $\Delta \dot{v}$ will be about $12 \mathrm{~mm}^{3} / \mathrm{s}$. For example, arbitrarily assuming the excess pore water pressure measured by the cone, $\left(u_{\mathrm{a}}-u_{\mathrm{s}}\right)$, is $300 \mathrm{kPa}$, gives $i_{a} \approx 1720$, as calculated from equation (7). With a flow area of $2 \pi a^{2}=2000 \mathrm{~mm}^{2}$, a value of $k \approx 3.5 \times 10^{-9} \mathrm{~m} / \mathrm{s}$ can be evaluated from equation (8a). This simple calculation indicates that the estimated value of $k$ is at least within the range of expectation and experience for clay soils.

In summary, it is proposed that a bi-linear relationship should be adopted between $K_{\mathrm{D}}$ and $B_{\mathrm{q}} Q_{\mathrm{t}}$ in double logarithmic scales, as shown in Fig. 4, in order to evaluate values of the hydraulic conductivity $k$ from piezocone sounding records. Further, it is suggested that this bi-linear relationship can be applied across a range of soils from sands to clays.

As in the original method by Elsworth \& Lee (2005, 2007), the proposed method is based on the assumption that a uCPT test will induce positive excess pore pressure in the soil around the cone. However, for heavily overconsolidated clay deposits and denser sand deposits, penetration of a cone may actually induce dilatancy of the soil around the cone. This dilatancy will tend to reduce the value of the positive pore water pressure generated in the soil, or even result in negative excess pore water pressures (Burns \& Mayne, 1998; Sully et al., 1999). Therefore it is suggested that the proposed method is applicable only to normally or lightly overconsolidated clayey deposits and loose sandy deposits.

\section{APPLICATION TO CASE HISTORIES \\ Tests at Saga, Japan}

On the Saga plain, around the Ariake Sea in Japan, there exists a clayey soil deposit with a thickness typically between 10 and $30 \mathrm{~m}$, which is known as Ariake clay. In this area, a highway project is currently under construction, and as part of the site investigation along the route of the highway, piezocone soundings were conducted adjacent to 23 boreholes. The test locations are shown in Fig. 5 (Ariake Sea Coastal Road Development Office (ASCRDO), Saga Prefecture, 2008). All the field data presented for the Saga case study have been kindly provided by ASCRDO (2008).

Within the test area, the thickness of the Ariake clay deposit is between 10 and $20 \mathrm{~m}$. Fig. 6 shows a typical soil profile and some of the physical and mechanical properties at the location of test no. 1 . In this figure, $\gamma_{t}$ is the total unit weight, $e$ is the void ratio, $w_{\mathrm{n}}$ is the natural water content, $w_{\mathrm{L}}$ is the liquid limit, $w_{\mathrm{P}}$ is the plastic limit, $p_{\mathrm{c}}^{\prime}$ is the preconsolidation pressure, $C_{\mathrm{c}}$ is the compression index, $c_{\mathrm{v}}$ is the coefficient of consolidation in the vertical direction and $k_{\mathrm{v}}$ is the hydraulic conductivity measured in the vertical direction. The listed values of $c_{\mathrm{V}}$ and $k_{\mathrm{v}}$ are for consolidation stresses from $9.8 \mathrm{kPa}$ to $1254 \mathrm{kPa}$. Ariake clay is a sensitive and highly compressible clay. For most cases the plasticity index is about 50 and the natural water content is greater than $100 \%$, slightly higher than the corresponding liquid limit.

The piezocones used in the Saga case study had an apex angle of $60^{\circ}$ and tip area of $1000 \mathrm{~mm}^{2}$, and the filter for pore water pressure measurement was at the shoulder of the cone. In each case the penetration rate adopted was $20 \mathrm{~mm} / \mathrm{s}$. To ensure saturation of the filter of the pore water pressure

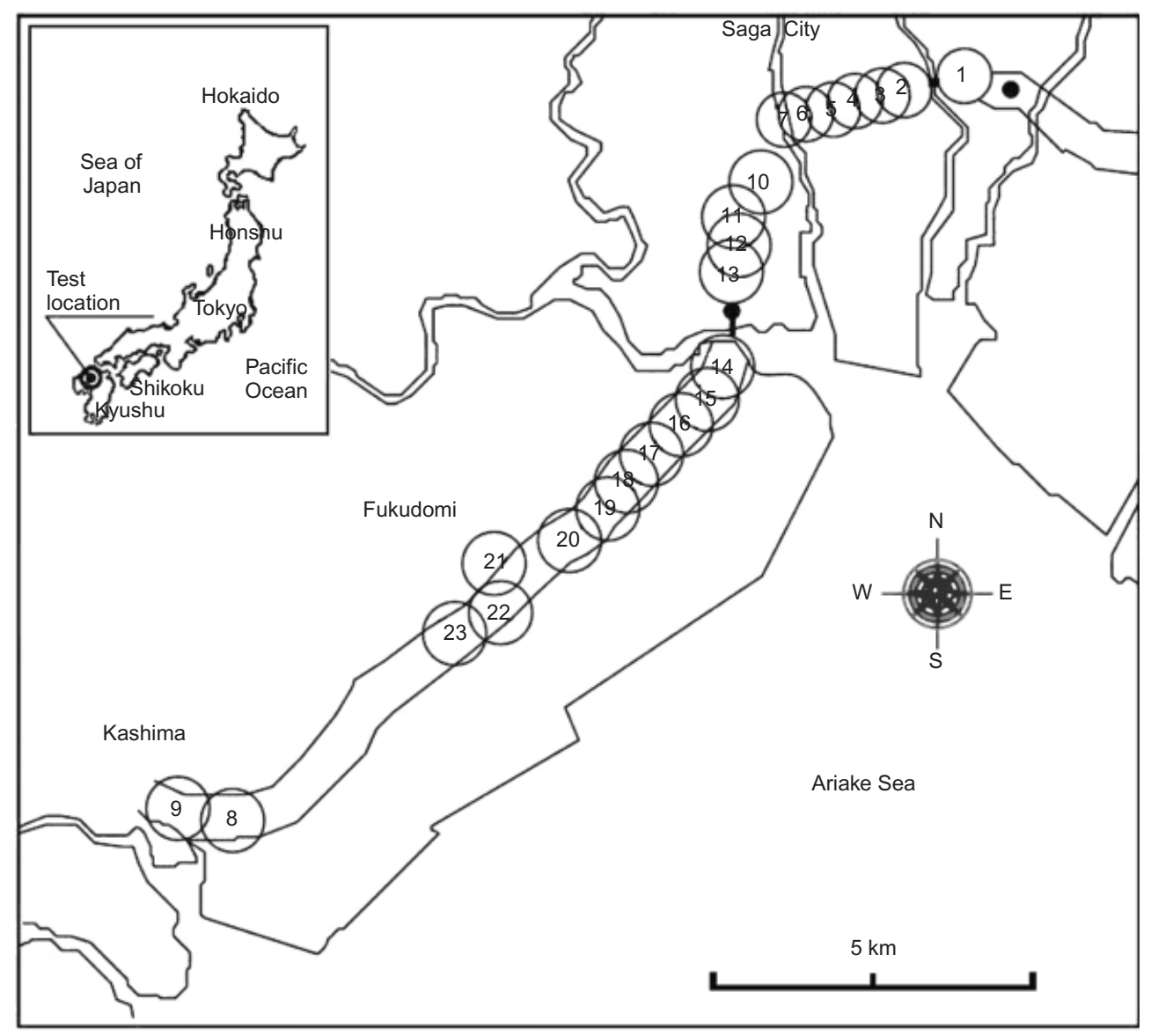

Fig. 5. Locations of the piezocone soundings at Saga 


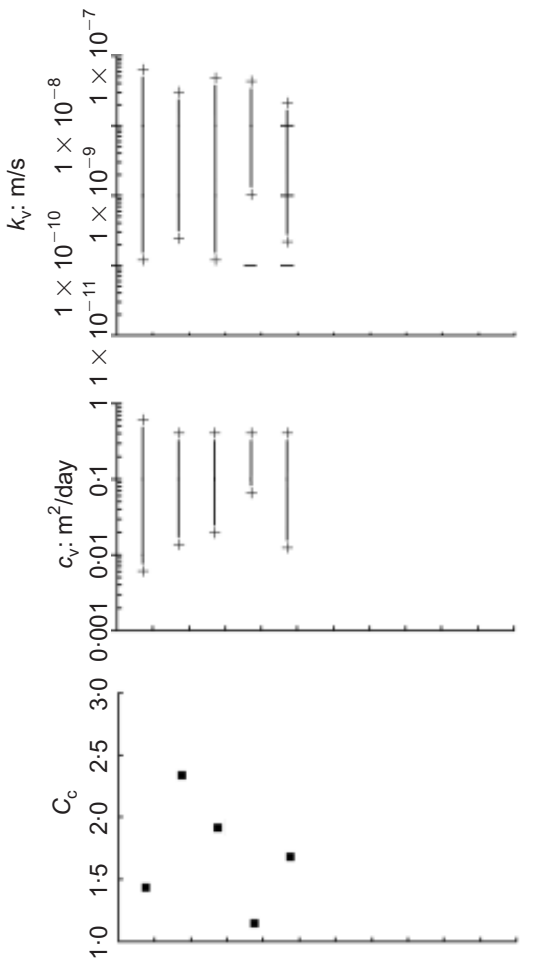

sensor, the filter was placed in boiling water for about $1 \mathrm{~h}$ on the day before the field measurement. From there it was put into a container filled with de-aired water and brought to the field and assembled just before the test (personal communication with Shyoji Nomura at Nihon-Chiken Co., Ltd, Japan, 2008). At these 23 test locations, undisturbed soil samples were obtained using Japanese thin wall samplers in accordance with JGS 1221-2003 (JGS, 2003), and laboratory consolidation tests were conducted in accordance with JIS A 1217 (JSA, 2000) on many samples.

Values of $k$ from the piezocone sounding records determined using the modified method described previously have been designated as $k_{\mathrm{hp}}$. The deduced values of $k_{\mathrm{hp}}$ are compared with the laboratory $k_{\mathrm{v}}$ values corresponding to the in situ vertical effective stress, $\sigma_{\mathrm{v} 0}^{\prime}$, estimated at the depth from which the sample was recovered.

In terms of the level of agreement between $k_{\mathrm{hp}}$ and $k_{\mathrm{v}}$, the 23 tests conducted at the Saga test site can be divided into two types: type I, where either good or at least reasonable agreement was found between the deduced field value of $k_{\mathrm{hp}}$ and the measured laboratory value of $k_{\mathrm{v}}$; and type II, for which $k_{\mathrm{hp}}>k_{\mathrm{v}}$. Twelve of the 23 tests are of type I (test nos $1,5,8,9,10,11,14,15,18,19,20$ and 21). Typical piezocone measurements of $q_{\mathrm{t}}$ and $u$ and a comparison of the deduced $k$ values are plotted in Fig. 7 for test no. 14 . Eleven of the 23 tests conducted at Saga are of type II (test nos 2, 3, 4, 6, 7, 12, 13, 16, 17, 22 and 23), and typical results are given in Fig. 8 for test no. 22.

Comparing Figs 7 and 8, the obvious difference is that the groundwater level at the location of test no. 22 (Fig. 8) was about $2.20 \mathrm{~m}$ lower than that of test no. 14 (Fig. 7). The lower groundwater level means a larger value of initial (in situ) vertical effective stress $\sigma_{\mathrm{v} 0}^{\prime}$ at the same depth. If the measured values of $u_{\mathrm{a}}$ are the same at a given depth, a larger value of $\sigma_{\mathrm{v} 0}^{\prime}$ will result in a lower value of $B_{\mathrm{q}} Q_{\mathrm{t}}$ and therefore a larger value of $K_{\mathrm{D}}$, and ultimately a larger estimated value of $k_{\mathrm{hp}}$. Among the 11 tests classified as type II, in seven of them the groundwater level was more than $3.0 \mathrm{~m}$ below the local ground surface; and among the 12 tests classified as type I, in eight of them the groundwater level was less than $2.0 \mathrm{~m}$ below the local ground surface. However, the groundwater levels referred to here were all measured at the time of field boring. Since groundwater levels often change over time, the reported levels might not be the exact groundwater levels at the time the uCPT was conducted. Therefore, when using uCPT soundings to estimate $k_{\mathrm{hp}}$, it is important to obtain an accurate measurement of the groundwater level. One possible solution would be to measure the water level in the hole left after the uCPT test has been conducted.

A comparison of the deduced values of $k_{\mathrm{hp}}$ and $k_{\mathrm{v}}$ is summarised in Fig. 9 for all 23 tests conducted at Saga. In two cases, one corresponding to test no. 1 conducted at $1.4 \mathrm{~m}$ depth and the other for test no. 9 conducted at a depth of $4.4 \mathrm{~m}$, the deduced values of $k_{\mathrm{hp}}$ are more than three orders of magnitude higher than the corresponding values of $k_{\mathrm{v}}$, and so they have been excluded from the figure. For all tests, as a general tendency the deduced value of $k_{\mathrm{hp}}$ is larger than the corresponding measured laboratory value of $k_{\mathrm{v}}$. However, it is noted that there are eight points for which $k_{\mathrm{hp}}$ is more than 20 times the corresponding value of $k_{\mathrm{v}}$, and their corresponding test numbers and depths are indicated in the figure. All these points correspond to uCPT test locations which were just below groundwater level, and in some cases the tests were conducted very close to the interface between a sandy layer and a clayey layer (tests nos 6 and 7). It seems that at these locations the interpreted $k_{\mathrm{hp}}$ value may be less reliable. Except for these particular eight test points, all other test points are spread around the line 

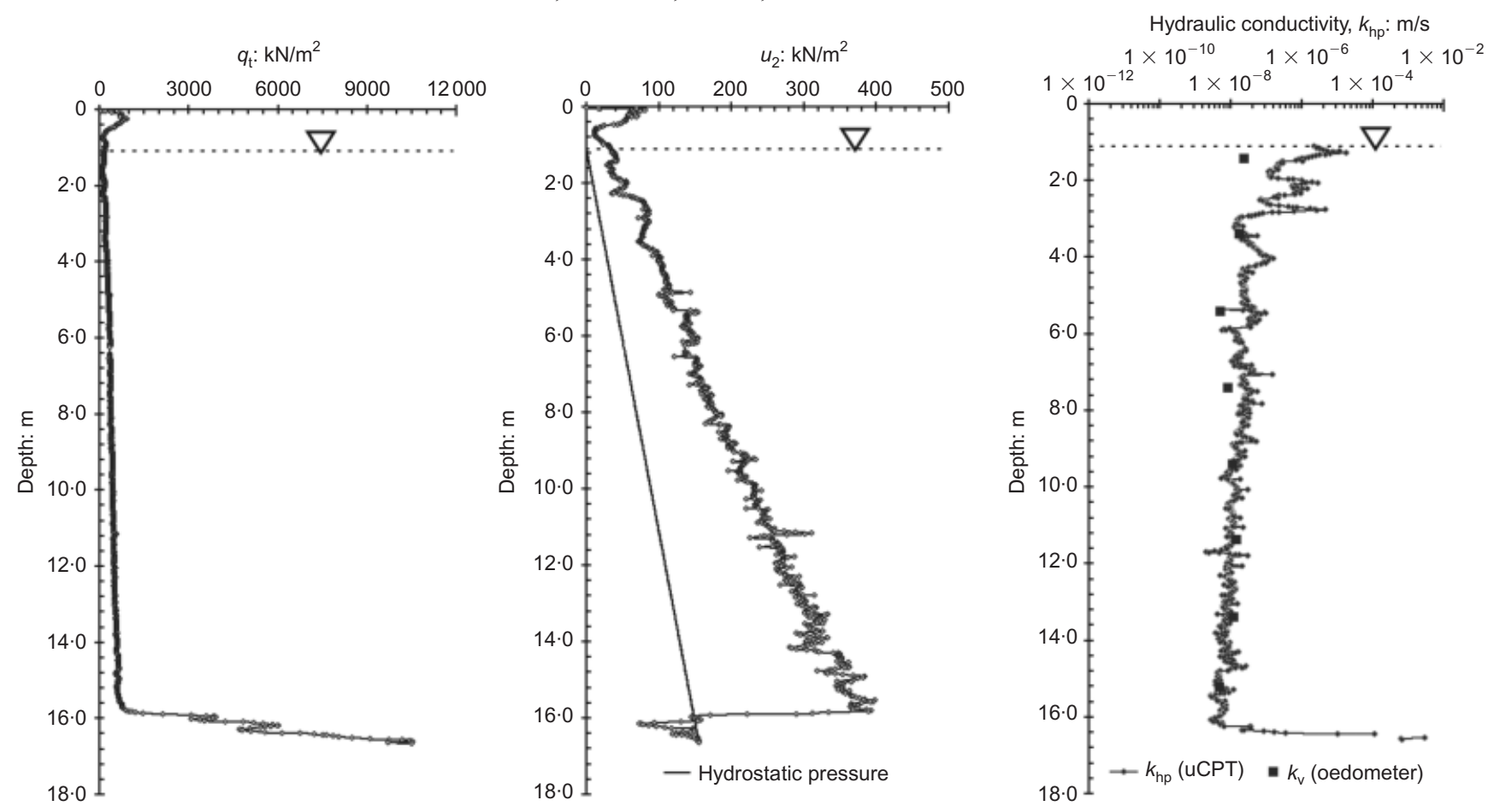

Fig. 7. Results of test no. 14 (type I)
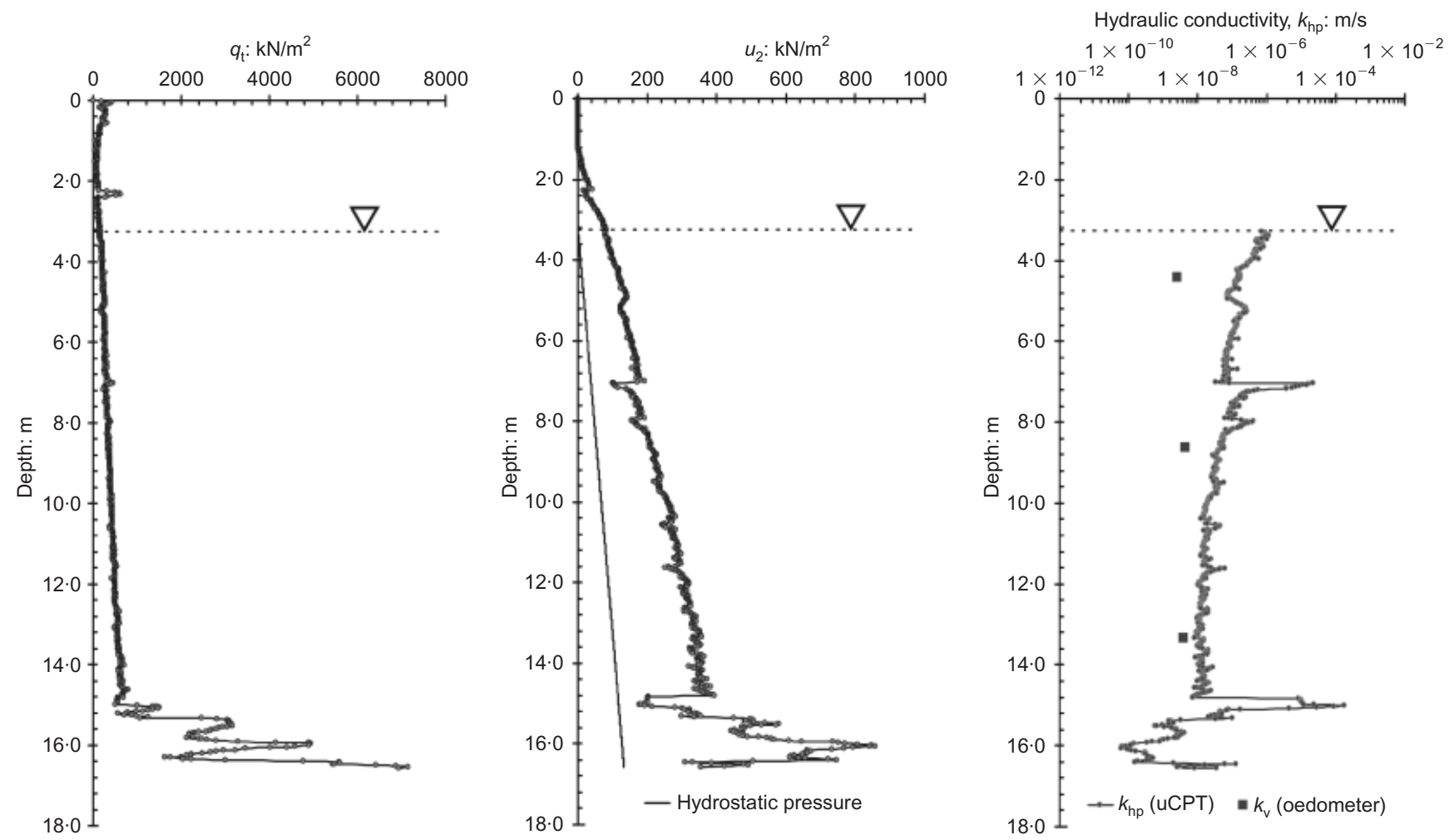

Fig. 8. Results of test no. 22 (type II)

defined by $k_{\mathrm{hp}}=2 k_{\mathrm{v}}$ and in a band between $k_{\mathrm{hp}}=0 \cdot 2 k_{\mathrm{v}}$ and $k_{\mathrm{hp}}=20 k_{\mathrm{v}}$.

Park (1994) conducted oedometer tests on Ariake clay samples cut in both the vertical and horizontal directions with respect to the in situ orientation, and reported that the measured ratio $k_{\mathrm{h}} / k_{\mathrm{v}}$ was about $1 \cdot 5$. Jia (2010) conducted constant rate of strain (CRS) consolidation tests on undisturbed Ariake clay samples under both vertical and radial (horizontal) drainage conditions, and a $k_{\mathrm{h}} / k_{\mathrm{v}}$ ratio of about
1.7 was reported. These particular findings were taken into account previously when proposing the $B_{\mathrm{q}} Q_{\mathrm{t}}-K_{\mathrm{D}}$ relationship for $B_{\mathrm{q}} Q_{\mathrm{t}}>0.45$ (equation (11)).

The uCPT results and the laboratory-measured $k_{\mathrm{v}}$ values are presented in the form of a plot of $K_{\mathrm{D}}$ against $B_{\mathrm{q}} Q_{\mathrm{t}}$ in Fig. 10 (using equation (10) and replacing $k$ by $k_{\mathrm{v}}$ in calculating $K_{\mathrm{D}}$ ) to show how close these data points for Ariake clay from Saga lie to the proposed bi-linear relationship. The data points are scattered around the proposed line, 


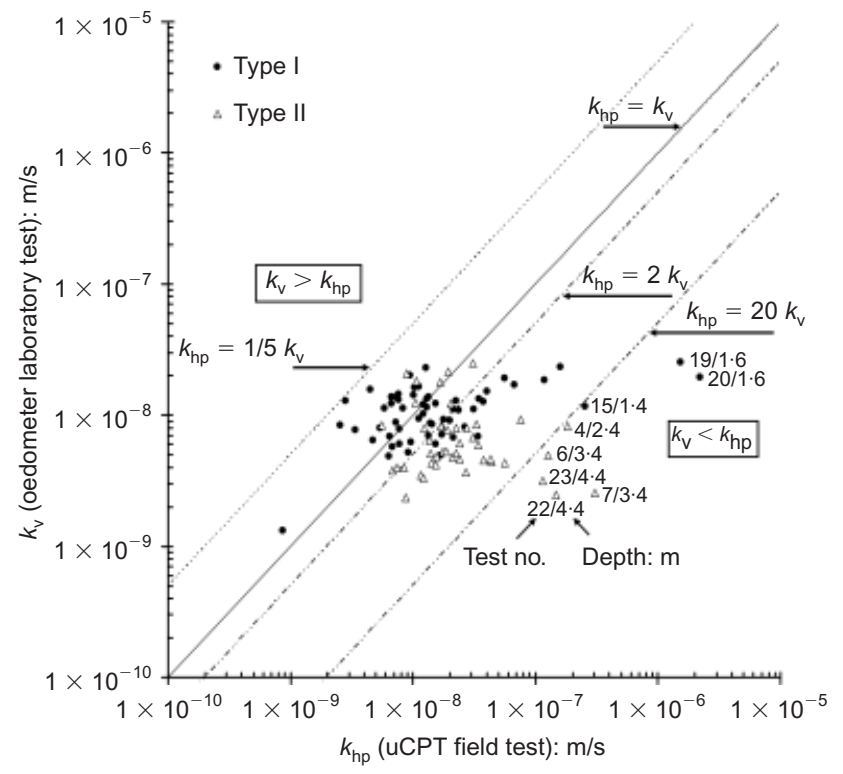

Fig. 9. Comparison of $k_{\mathrm{hp}}$ with $k_{\mathrm{v}}$ for cases in Saga

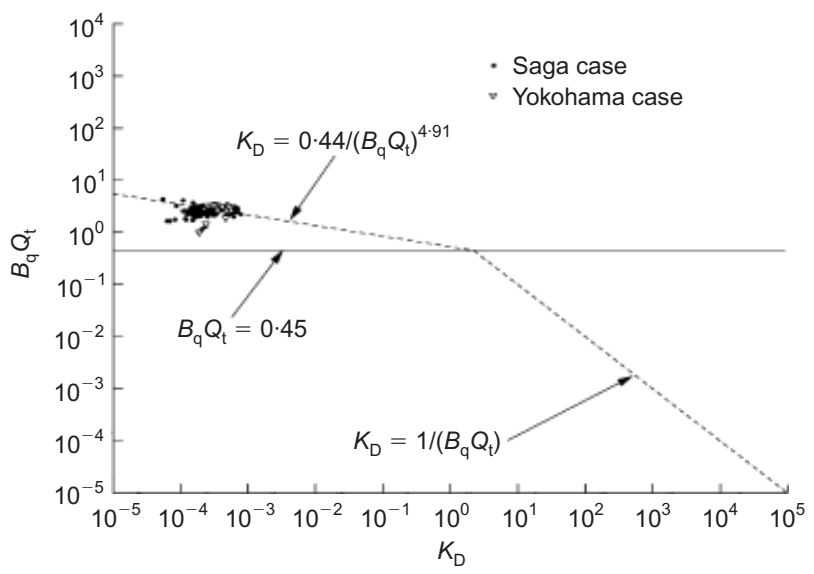

Fig. 10. The uCPT results and the laboratory-measured $k_{\mathrm{v}}$ values in $K_{\mathrm{D}}$ against $B_{\mathrm{q}} Q_{\mathrm{t}}$ form

but there are more data points below the line, which is consistent with the information revealed in Fig. 9 that generally $k_{\mathrm{hp}}>k_{\mathrm{v}}$.

From the results shown in Figs $7-10$, it is concluded that the proposed modified method of interpreting uCPT tests is applicable to the piezocone tests conducted on the Saga plain in Japan. It is encouraging that the values of $k_{\mathrm{h}}$ for soils ranging from sands to clays in normally or lightly overconsolidated conditions may be continuously and reasonably evaluated from piezocone sounding records using this modified method.

Tests at Yokohama, Japan

In 2007 the Japanese Geotechnical Society (JGS) organised an activity that involved conducting piezocone soundings by 10 different organisations at the same site (in an area $5 \mathrm{~m}$ by $20 \mathrm{~m}$ ) in Yokohama, Japan (Suemasa et al., 2009). The soil profile and some of the measured physical and mechanical properties of the soils at this site are given in Fig. 11. The soil deposit consists of a sandy clay layer at the ground surface, with a thickness of about $4.0 \mathrm{~m}$, underlain by a fine sand layer to a depth of about $10 \cdot 0 \mathrm{~m}$. Below the fine sand is another sandy clay layer about $10.0 \mathrm{~m}$ thick. All test data shown in Fig. 11 are taken from the Report of
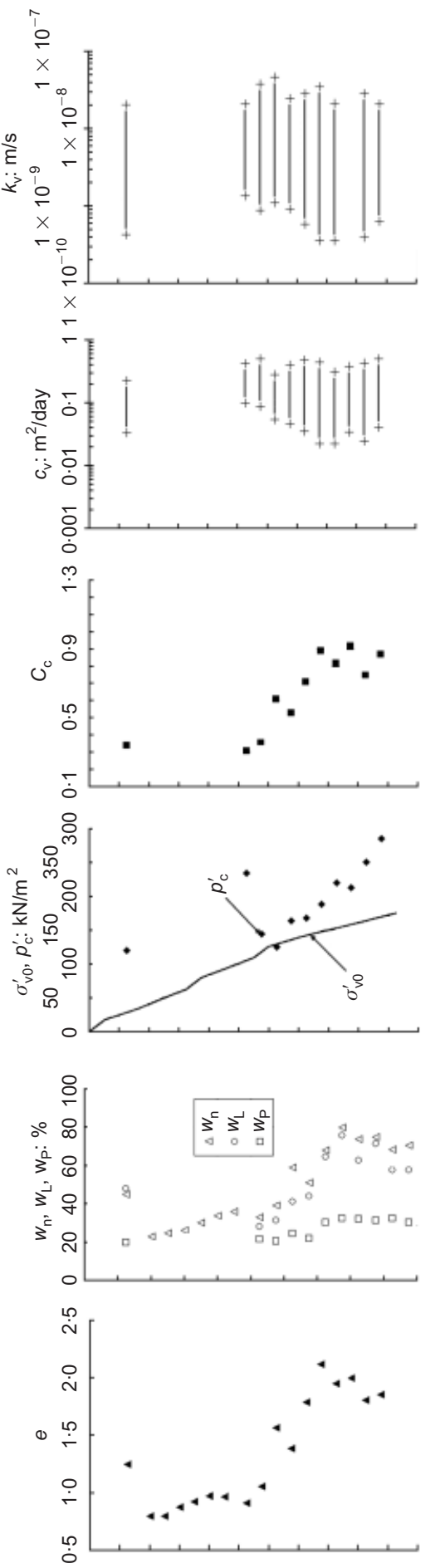
simultaneous field CPT tests produced by the Research Committee for the project entitled 'Advanced CPT Technology and Its Application to Design, Environmental Assessment and Disaster Prevention', referred to here for brevity as JGS (2009). As reported by Suemasa et al. (2009), discrepancies between the results of the 10 organisations were relatively small, and so detailed data from only one organisation (organisation C) have been reported here. Those data have been used to estimate the $k_{\mathrm{hp}}$ values of the soil deposit at this site.

The cone penetrometer used by organisation $\mathrm{C}$ had a diameter of $35.7 \mathrm{~mm}$ and an apex angle of $60^{\circ}$. The pore water pressure gauge was located at the shoulder of the cone. The filter for pore water pressure measurement was made of ceramic, and was de-aired by vacuum pressure before the tests were conducted (Suemasa et al., 2009). The rate of penetration of the cone was $20 \mathrm{~mm} / \mathrm{s}$ in each test. The measured values of $q_{\mathrm{t}}$ and $u$, and a comparison of the deduced values of $k_{\mathrm{hp}}$ (uCPT) and $k_{\mathrm{v}}$ (oedometer), are depicted in Fig. 12 for different depths, and the same data are also plotted in Fig. 13 in the form $k_{\mathrm{hp}}$ against $k_{\mathrm{v}}$. For this case there are more points for which the estimated $k_{\mathrm{hp}}$ values are smaller than the values of $k_{\mathrm{v}}$ measured in independent laboratory tests. The exact reason for this tendency is not clear, but one possible explanation may be that the values of $k_{\mathrm{v}}$ obtained from the oedometer tests might have been overestimated. The Appendix of JGS (2009) contains a summary of the procedure used to interpret the oedometer tests. In this Appendix a parameter $r$ is defined as the ratio of $d_{1} / d_{24}$, where $d_{1}$ is the settlement corresponding to the end of primary consolidation determined by the root time method, and $d_{24}$ is the settlement $24 \mathrm{~h}$ after the application of a load increment. Normally the value of $r$ is around 0.5 or more for clayey soils (JGS, 2000). For consolidation stresses less than $200 \mathrm{kPa}$ (the range of interest in this study), the reported values of $r$ are mostly between 0.2 and 0.3 . Smaller values of $r$ imply shorter times corresponding to $90 \%$ degree of consolidation, in which case larger values of $k_{\mathrm{v}}$ will be calculated. Since

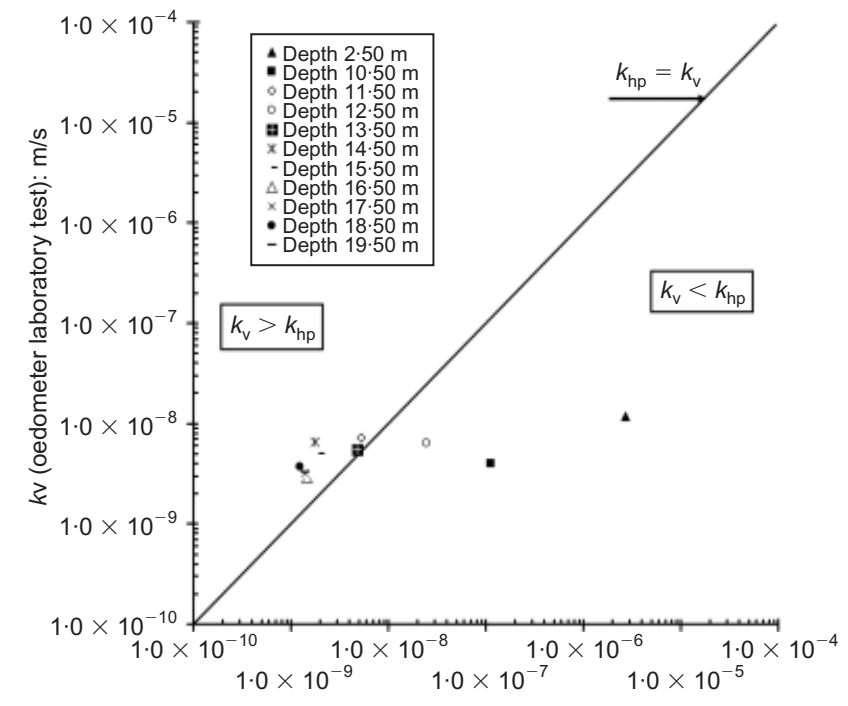

Fig. 13. Comparison of $k_{\mathrm{hp}}$ with $k_{\mathrm{v}}$ at Yokohama

the settlement-time curves obtained in the oedometer tests are not available, a more definitive comment cannot be made. However, there may have been problems in interpreting the oedometer test results, or in conducting the test itself. Another possible reason for $k_{\mathrm{hp}}<k_{\mathrm{v}}$ in some of the Yokohama cases is that there may have been some difference in the groundwater levels between the time of boring and the time the field uCPT test was conducted. For the method proposed, and for a given measured value of $u_{\mathrm{a}}$, reducing the initial vertical effective stress (by increasing the static water pressure) will tend to reduce the estimated value of $k_{\mathrm{hp}}$. Also, generally with a smaller initial vertical effective stress, a larger $k_{\mathrm{v}}$ value will be interpolated from laboratory oedometer test results. At the Yokoyama site, at the time of boring, the groundwater level was $1.05 \mathrm{~m}$ below the ground surface. There is no information about the groundwater level at the time of the field uCPT test. However, for a previous
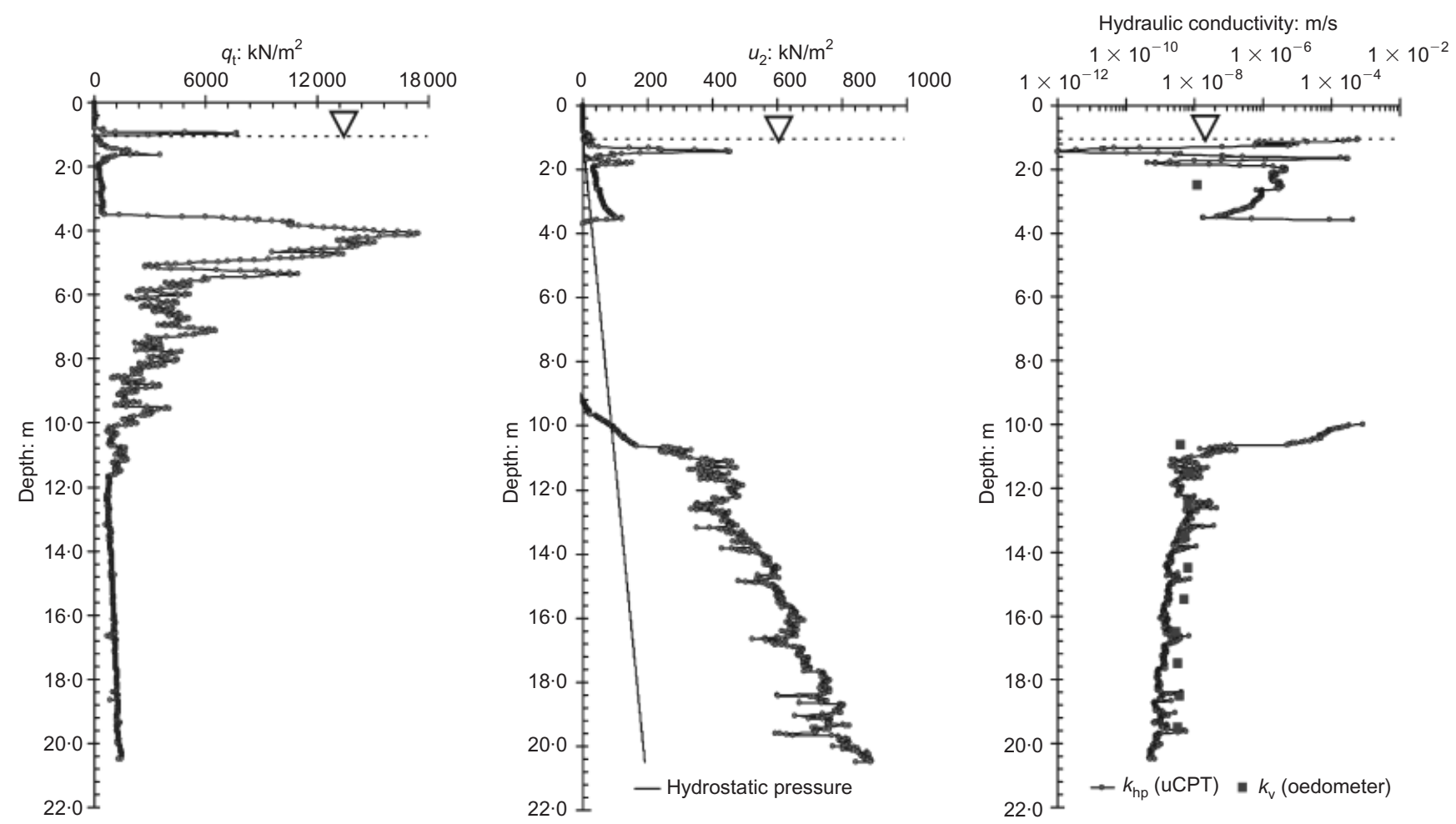

Fig. 12. Test results at the site in Yokohama 
existing borehole (about $100 \mathrm{~m}$ away from the site) the groundwater was recorded at $2.41 \mathrm{~m}$ below the ground surface (Suemasa et al., 2009). The data points of the Yokohama case are also shown in Fig. 10, and most of these points are above the proposed line.

The data presented here for the Yokohama site provide further confidence in the reliability of the proposed modified method of interpreting uCPT soundings.

\section{CONCLUSION}

Elsworth \& Lee $(2005,2007)$ proposed an explicit equation for evaluating the in situ hydraulic conductivity of soils in the horizontal direction, $k_{\mathrm{hp}}$, from piezocone sounding records. However, the equation they proposed can be used reliably only for soils with a hydraulic conductivity typical of fine sand or soils with higher values of hydraulic conductivity. The main obstacle to using their methodology for clay soils is that the penetration process occurs in conditions very close to undrained, and does not involve significant pore water flow within the soil in the vicinity of the cone tip.

In this paper it was reasoned that, during a piezocone penetration in clayey soil, a significant hydraulic gradient will certainly be generated around the cone tip. By applying Darcy's law over the finite time required for an increment of cone penetration, it was argued that there will be some water movement around the cone, albeit very small if the soil is fine grained, such as is the case for clay. Based on this argument, and observing the test data collected by Elsworth $\&$ Lee, a bi-linear relation between the dimensionless piezocone sounding metric $B_{\mathrm{q}} Q_{\mathrm{t}}$ and the dimensionless hydraulic conductivity index $K_{\mathrm{D}}$ plotted on double logarithmic scales has been proposed for soils ranging from sands to clays. These revised relationships can be used to evaluate values of $k_{\text {hp }}$ from piezocone sounding records, thus extending the range of application of the method first proposed by Elsworth \& Lee to normally or lightly overconsolidated clayey deposits and loose sandy deposits.

The new equations proposed in this paper were used to evaluate $k_{\mathrm{hp}}$ values from 24 independent piezocone sounding records conducted in clayey deposits in Japan. Among them, 23 soundings were from Saga and one was from Yokohama. For all these cases the values of the corresponding hydraulic conductivity in the vertical direction, $k_{\mathrm{v}}$, measured in laboratory oedometer tests were also available. Comparing the deduced $k_{\mathrm{hp}}$ values with the laboratory measured $k_{\mathrm{v}}$ values indicates that generally $k_{\mathrm{hp}}$ is larger than $k_{\mathrm{v}}$, and that most data are spread around the $k_{\mathrm{hp}}=2 k_{\mathrm{v}}$ line. It is generally accepted that, owing to the stratification of natural soil deposits, the hydraulic conductivity in the horizontal direction, $k_{\mathrm{h}}$, is usually larger than that in the vertical direction, $k_{\mathrm{v}}$. Most of the test data examined here are from the Ariake clay deposit in Saga, Japan, and the ratio of 2 observed in the uCPT tests is close to the laboratory hydraulic conductivity ratio $k_{\mathrm{h}} / k_{\mathrm{v}}=1.5$ to 1.7 generally observed for Ariake clay. Consequently, it is suggested that the proposed method can be used to provide reliable estimates of the in situ $k_{\mathrm{h}}$ values. However, it is noted that for the Yokohama site most of the deduced values of $k_{\mathrm{hp}}$ were smaller than the corresponding laboratory values of $k_{\mathrm{v}}$. The exact reason is not yet clear, but may be related to difficulties in deducing the laboratory values of $k_{\mathrm{v}}$ for this site.

It is believed that the revised method proposed here forms a sound framework for evaluating field values of $k_{\mathrm{h}}$ from piezocone sounding records. Application of the method can provide a continuous profile of $k_{\mathrm{h}}$ with depth, which will be very useful for civil engineering design.

\section{ACKNOWLEDGEMENT}

M. Koga, director of the Ariake Sea Coastal Road Development Office, Saga Prefecture, Japan, permitted the publication of the field data for the cases in Saga, Japan. His generous support of this research is highly appreciated.

\section{NOTATION}

a piezocone radius

$B_{\mathrm{q}} \quad$ dimensionless pore pressure ratio

$C_{\mathrm{c}}$ compression index

$c_{\mathrm{V}}$ coefficient of consolidation in vertical direction

$d_{1}$ settlement corresponding to end of primary consolidation

$d_{24}$ settlement $24 \mathrm{~h}$ after application of a load increment

$e$ void ratio

$f_{\mathrm{s}}$ sleeve friction

$i$ hydraulic gradient

$i_{a}$ hydraulic gradient at radius $r=a$

$k$ hydraulic conductivity

$k_{\mathrm{h}}$ hydraulic conductivity in horizontal direction

$k_{\text {hp }}$ hydraulic conductivity in horizontal direction estimated from piezocone sounding record

$k_{\mathrm{v}}$ hydraulic conductivity in vertical direction

$K_{\mathrm{D}}$ dimensionless hydraulic conductivity

OCR overconsolidation ratio

$p_{\mathrm{c}}^{\prime}$ preconsolidation pressure

$q$ rate of pore water flow

$q_{\mathrm{t}}$ corrected tip resistance

$Q_{\mathrm{t}}$ normalised dimensionless cone resistance

$r$ radial distance

$r$ ratio of $d_{1} / d_{24}$ from consolidation test

$U$ rate of cone penetration

$u$ pore water pressure

$u_{\mathrm{a}}$ absolute pore water pressure

$u_{\mathrm{s}}$ initial static pore water pressure

$\Delta \dot{v}$ rate of volume penetration of a cone

$w_{\mathrm{n}}$ natural water content

$w_{\mathrm{L}}$ liquid limit

$w_{\mathrm{P}}$ plastic limit

$\alpha_{1}$ a constant

$\gamma_{\mathrm{w}}$ unit weight of water

$\gamma_{\mathrm{t}}$ total unit weight of soil

$\sigma_{\mathrm{v} 0}$ initial total vertical stress

$\sigma_{\mathrm{v} 0}^{\prime} \quad$ initial vertical effective stress

\section{REFERENCES}

ASCRDO (2008). Site investigation reports, along the route of the Saga Section, around Ariake Sea Highway, Saga, Japan. Ariake Sea Coastal Road Development Office (in Japanese).

Burns, S. E. \& Mayne, P. W. (1998). Monotonic and dilatory pore pressure decay during piezocone tests in clay. Can. Geotech. J. 35, No. 6, 1063-1073.

Campanella, R. G. \& Robertson, P. K. (1988). Current status of the piezocone test. In Penetration testing 1988 (ed. J. Ruiter), pp. 93-116. Rotterdam: Balkema.

Cetin, K. O. \& Ozan, C. (2009). CPT-based probabilistic soil characterization and classification. J. Geotech. Geoenviron. Engng 135, No. 11, 84-107.

Clarke, B. G., Carter, J. P. \& Wroth, C.P. (1979). In situ determination of the consolidation characteristics of saturated clays. Proc. 7th Eur. Conf. Soil Mech. Found. Engng, Brighton 2, 207-211.

Douglas, B. J. \& Olsen, R. S. (1981). Soil classification using electric cone penetrometer. In Cone penetration testing and experience, Proceedings of the ASCE National Convention, St Louis, pp. 209-227. ASCE.

Danziger, F. A. B., Almeida, M. S. S. \& Sills, G. C. (1997). The significance of the strain path analysis in the interpretation of piezocone dissipation data. Géotechnique 47, No. 5, 901-914, doi: $10.1680 /$ geot.1997.47.5.901.

Elsworth, D. (1991). Dislocation analysis of penetration in saturated porous media. J. Engng. Mech. Div. ASCE 117, No. 2, 391-408. Elsworth, D. \& Lee, D. S. (2005). Permeability determination from 
on-the-fly piezocone sounding. J. Geotech. Geoenviron. Engng 131, No. 5, 643-653.

Elsworth, D. \& Lee, D. S. (2007). Limits in determining permeability from on-the-fly uCPT Sounding. Géotechnique 57, No. 8, 769-685, doi: $10.1680 /$ geot.2007.57.8.769.

Gupta, R. C. \& Davidson, J. L. (1986). Piezoprobe determined coefficient of consolidation. Soils Found. 26, No. 3, 12-22.

Jia, R. (2010). Consolidation behavior of Ariake clay under constant rate of strain. $\mathrm{PhD}$ dissertation, University of Saga.

JGS (2000). Soil testing methods and explanations. Tokyo: Japanese Geotechnical Society (in Japanese).

JGS (2003). Method for obtaining undisturbed samples using fixed piston thin wall sampler, JGS 1221-2003. Tokyo: Japanese Geotechnical Society (in Japanese).

JGS (2009). Report of simultaneous field uCPT tests. Research Committee of Advanced CPT Technology and its Applications to Design, Environment Assessment and Disaster Prevention. Tokyo: Japanese Geotechnical Society.

JSA (2000). Method for one-dimensional consolidation properties of soils using incremental loading, Japanese Industrial Standard JIS A 1217. Tokyo: Japanese Standards Association.

Konrad, J. M. \& Law, K. (1987). Undrained shear strength from piezocone tests. Can. Geotech. J. 24, No. 3, 392-405.

Leroueil, S., Bouclin, G., Tavenas, F., Bergeron, L. \& Rochelle, P. L. (1990). Permeability anisotropy of natural clays as a function of strain. Can. Geotech. J. 27, No. 6, 568-579.

Lunne, T., Robertson, P. K. \& Powell, J. J. M. (1997). Cone penetration testing in geotechnical practice. London: E\&FN Spon.

Lu, Q., Randolph, M. F., Hu, Y. \& Bugarski, C. A. (2004). Numerical study of cone penetration in clay. Géotechnique 54, No. 4, 257-267, doi: 10.1680/geto.2004.54.4.257.

Mitchell, J. K. \& Brandon, T. L. (1998). Analysis and use of CPT in earthquake and environmental engineering. In Geotechnical site characterization (eds P. K. Robertson and P. W. Mayne), Vol. 1, pp. 69-96. Rotterdam: Balkema.

Park, Y. M. (1994). A research on the mechanical properties of lowland marine clay and vertical drain improvement method. $\mathrm{PhD}$ dissertation, University of Saga.

Rad, N. S. \& Lunne, T. (1988). Direct correlation between piezocone test results and undrained shear strength of clay. Proc. Penetration Testing 1988 (ed. ISOPT-1), Orlando 2, 911917.

Randolph, M. F. \& Wroth, C. P. (1979). An analytical solution for the consolidation around a driven pile. Int. J. Numer. Anal. Methods Geomech. 3, No. 3, 217-229.

Robertson, P. K. (1990). Soil classification using the cone penetration test. Can. Geotech. J. 27, No. 1, 151-158.

Robertson, P. K., Sully, J. P., Woeller, D. J., Lunne, T., Powell, J. J. M. \& Gillespie, D. G. (1992). Estimating coefficient of consolidation from piezocone test. Can. Geotech. J. 29, No. 4, $539-550$.

Sills, G. C. \& Hird, C. C. (2005). Coefficient of consolidation from piezocone measurements. Géotechnique 55, No. 8, 597-602, doi: $10.1680 /$ geot.2005.55.8.597.

Suemasa, N., Katagiri, M. \& Iizawa, M. (2009). Comparative study on the performance of various electric cone penetrations in 2007. Jpn Geotech. Engng J. 57, No. 8, 16-19.

Sully, J. P., Robertson, P. K., Campanella, R. G. \& Woeller, D. J. (1999). An approach to evaluation of field CPTU dissipation data in overconsolidated fine-grained soils. Can. Geotech. J. 36, No. 2, 369-381.

Teh, C. I. \& Houlsby, G. T. (1991). An analytical study of the cone penetration test in clay. Géotechnique 41, No. 1, 17-34, doi: 10.1680/geot.1991.41.1.17.

Wroth, C. P. (1984). The interpretation of in situ soil tests. Géotechnique 34, No. 4, 449-89, doi: 10.1680/geot.1984. 34.4.449. 